\title{
LAS AGENDAS DE CAMBIO CLIMÁTICO Y DE DESARROLLO HUMANO SOSTENIBLE EN LAS CUMBRES DE PARÍS Y NUEVA YORK: UNA HISTORIA DE DOS CIUDADES
}

\author{
Autores: Andrés González García1, José Carlos Romero Mora, Adela Conchado Rodríguez, \\ Pedro Linares Llamas \\ Instituto de Investigación Tecnológica (IIT), Universidad Pontificia Comillas \\ Maryse Labriet \\ Eneris Environment Energy Consultants y Fundación Energía Sin Fronteras
}

\section{Resumen}

Las agendas Climática y de Desarrollo Sostenible puestas en marcha en París y Nueva York a finales de 2015 marcan un hito fundamental en los esfuerzos que a escala global van a realizar países, instituciones internacionales, sociedad civil y también los individuos para conformar un equilibrio global y sostenible en lo económico, social y medioambiental, que no comprometa el bienestar de las gene-

\footnotetext{
${ }^{1}$ Andres. Gonzalez@iit.comillas.edu
} 
raciones futuras al tiempo que persigue un espacio justo, equitativo y seguro para todos en las próximas décadas. Ambas agendas, igual que ambos fenómenos, están complejamente interrelacionadas y requieren de un esfuerzo coordinado orientado a la acción y a la innovación para la consecución de sus diversos objetivos.

Palabras clave: Cambio Climático; mitigación; adaptación; Cumbre de París; COP21; Objetivos de Desarrollo Sostenible; Agenda Post 2015; acceso universal a la energía; innovación.

The agenda of climate change and sustainable development in Paris and New York forum: history of two cities

\begin{abstract}
The agendas for Climate Change and for Sustainable Development launched in Paris and New York in 2015 set a fundamental milestone in the efforts that countries, international institutions, civil society and individual people endeavor to make in order to build a global sustainable equilibrium which balances the economic, social and environmental dimensions, which does not compromise the well-being of future generations while pursuing a just, fair and safe space for humanity in the coming decades. Both agendas, as well as both issues, are complexly interrelated and require a coordinated effort towards action and innovation to achieve their multiple objectives.
\end{abstract}

Key words: Climate Change; mitigation; adaptation; Paris Agreement; COP21; Sustainable Development Goals; Post-2015 Agenda; universal access; energy; innovation.

\title{
1. INTRODUCCIÓN
}

«Era el mejor de los tiempos, era el peor de los tiempos, la edad de la sabiduría, y también de la locura; la época de las creencias y de la incredulidad; la era de la luz y de las tinieblas; la primavera de la esperanza y el invierno de la desesperación. Todo lo poseíamos, pero no teníamos nada; caminábamos en derechura al cielo y nos extraviábamos por el camino opuesto. En una palabra, aquella época era tan parecida a la actual...». (Dickens, 1859) 
Las recientes Cumbre Mundial sobre Desarrollo Sostenible (Nueva York, 25 a 27 de Septiembre de 2015) y XXI Conferencia Internacional sobre Cambio Climático (París, 30 de Noviembre a 12 de diciembre de 2015) marcan sendos hitos fundamentales y complementarios para marcar las agendas climáticas y de desarrollo global de las próximas décadas.

Nuestra particular historia de dos ciudades, París y Nueva York, trata de analizar las dos agendas desde el punto de vista de su características específicas y complementarias, en pos de un complejo y multifacético desarrollo sostenible en lo social, medioambiental y económico, conciliando sus escalas globales, nacionales y locales, y estableciendo un marco de referencia común, un conjunto de conceptos y significados expresado en un lenguaje compartido, que facilite la puesta en marcha de mecanismos, instituciones y redes de gobernanza a la medida de los objetivos que se plantean en ambas cumbres.

Es evidente que desafíos de esta magnitud no pueden abordarse sin la participación de gobiernos, empresas, organizaciones multilaterales y de la sociedad civil. Junto con los necesarios esfuerzos públicos, son necesarios también el concurso del capital privado y la involucración de la población, especialmente de aquellos más afectados por los esfuerzos y cambios a que nos enfrentamos. Cambios así requieren, siguiendo el esquema clásico de Douglas North (North, 1992, 1993), de un marco institucional, político, legal y regulatorio apropiado, junto con los mecanismos para evaluar y hacer cumplir los objetivos marcados, y fundamentado en una cultura de valores y comportamientos compartidos ordenada, en este caso, a mantener nuestro planeta y nuestra sociedad dentro de una hoja de ruta sostenible al tiempo que promueve el desarrollo, equilibrando los esfuerzos y beneficios para todos.

El objetivo de este artículo es mostrar cómo las agendas climáticas y de desarrollo sostenible recientemente acordadas marcan un punto de inflexión global en estas tres direcciones: el marco institucional (que deberá adaptarse para responder a ambas agendas), el impulso y control sobre las acciones y objetivos marcados (a través de los mecanismos, indicadores, marcos de seguimiento y revisión de los objetivos que establecen), y la promoción de una cultura común hacia el desarrollo sostenible. El texto recoge los conocimientos y las experiencias de diferentes autores, que en una u otra forma han participado en los procesos de construcción de los consensos de París y Nueva York. Comienza exponiendo el que a juicio de los autores es el paradigma actual de desarrollo humano sostenible, complejo y multidimensional. A continuación se describen brevemente los aspectos más notables de ambas cumbres. En la Sección 3 se analiza en qué forma ambas cuestiones se interrelacionan, destacando los aspectos clave que entrelazan la lucha contra el Cambio Climático (CC) y la consecución de los Objetivos de Desarrollo Sostenible (ODS) y en especial como ejemplo el Acceso Universal a la energía. La Sección 4 trata de exponer la necesidad de promover nuevas vías, y de la innovación en tecnologías, 
modelos de negocio, procesos y enfoques que, a juicio de los autores requieren ambas agendas para la consecución de los objetivos, para dar paso finalmente a las conclusiones del artículo.

\section{HISTORIA DE DOS CIUDADES}

\subsection{Desarrollo humano sostenible}

"A mediados del siglo XX, por primera vez, vimos nuestro planeta desde el espacio (...) Desde ahí vemos una esfera pequeña y frágil dominada no por la actividad humana y la edificación sino por un estampado de nubes, océanos, vegetación y suelos. La incapacidad de la Humanidad para encajar sus actividades en ese estampado está cambiando de manera esencial los sistemas planetarios. Muchos de tales cambios están acompañados de riesgos que amenazan la vida. Esta nueva realidad, de la que no hay escapatoria posible, debe reconocerse y atajarse."

El texto anterior está recogido en el primer capítulo del informe de las $\mathrm{Na}$ ciones Unidas Our Common Future, más conocido como Informe Brundtland (Brundtland, 1987), y que contribuyó de forma extraordinaria a la popularización del concepto de desarrollo sostenible. El informe tenía dos objetivos fundamentales: por un lado dar una visión lo más objetiva posible de la senda insostenible por la que estaba caminando el desarrollo humano y, por otro, incidir en la necesidad de un esfuerzo internacional que fuera capaz de revertir esta situación.

El informe Brundtland supuso un hito. Abrió los ojos a la comunidad internacional sobre un problema que, si no se atajaba, podría llegar a alterar el equilibrio natural que hace posible la vida humana en la tierra. Hoy, casi 30 años después, somos todavía mucho más conscientes del problema y de sus ramificaciones. Existen algunos elementos claves para entenderlo: según datos del Banco Mundial, la población mundial ha crecido desde los 3,01 miles de millones de personas en 1960 a los 7,27 en 2012, es decir, se ha producido un crecimiento de más del 140\% en 50 años. En paralelo, el incremento en el PIB mundial (en dólares constantes del 2005) pasó de 9,2 trillones de dólares en 1960 a 54,6 trillones en 2012, o lo que es lo mismo, se ha multiplicado casi por 6 en los últimos 50 años. En definitiva, estamos ante un escenario de crecimiento sin precedentes en la historia de la humanidad cuyo impacto sobre el planeta sospechamos que transita por una senda insostenible; una insostenibilidad, además, que no se limita a poner en riesgo los límites resilientes del planeta, sino que también se encuentra asociada a un nivel creciente de inequidad en la distribución de la riqueza que estamos generando. 
Muchas son las señales que confirman esta sospecha de que no vamos por el buen camino en ninguno de los dos aspectos. Baste poner como ejemplo los sucesivos informes del IPCC sobre calentamiento global. Si no se ponen freno a las emisiones de gases de efecto invernadero, a finales del siglo XXI podríamos encontrarnos con un escenario de aumento de la temperatura global superior a los 2 grados centígrados, hecho que podría resultar catastrófico para muchos ecosistemas. También por el lado de la inequidad las señales son preocupantes. Tomando como ejemplo EE.UU., vemos que el índice de Gini, que mide la desviación del equilibrio en la distribución de rentas, creció, según la OCDE, de 0,340 en 1987 a 0,380 en 2011. Puede parecer un número pequeño, pero dada la forma en que se construye el indicador, supone un trasvase de ingresos de más de un 10\% de las clases más desfavorecidas a las más ricas. Es decir, a pesar de que el PIB de EE.UU. en ese intervalo prácticamente se duplicó, la desigualdad en la distribución del mismo no ha hecho más que aumentar.

Muchos otros datos podríamos aportar para ilustrar que aquello que anticipó el Informe Brundtland no eran malos vaticinios sino realidades. El mundo avanza por patrones de crecimiento insostenibles, y esto es un problema de proporciones mayúsculas.

El primer paso a dar en la resolución de cualquier problema, sea de la índole que sea, es definirlo. Sin embargo para el caso del desarrollo sostenible este ejercicio ha resultado ser una quimera (Pezzey, 1997). Encontrar una definición que acote el problema de la sostenibilidad y que a la vez resulte operativa es una tarea no lograda hasta la fecha, a pesar de que se han hecho multitud de propuestas. Una de las más conocidas es la que planteó el propio informe Brundtland. Se decía en el citado informe que "desarrollo sostenible es aquel que asegura las necesidades del presente sin comprometer la capacidad de las futuras generaciones para enfrentarse a sus propias necesidades".

Esta conceptualización del desarrollo sostenible a partir de las necesidades supuso un gran paso adelante, pues consiguió plantear el problema en su doble horizonte intra e inter-generacional, e incidió en la necesidad de profundizar en las relaciones entre ellos. Sin embargo, dejaba abierta una pregunta que trataremos de analizar en este artículo: ¿qué necesidades son esas que hay que satisfacer en el presente y hacia el futuro?

Responder a esta pregunta exige entrar en el complejo problema del bienestar y las preferencias individuales. Dado que estas preferencias pueden cambiar de unos colectivos humanos a otros y entre generaciones, intentar acotar el problema del desarrollo sostenible a partir de las mismas suele conducir a un callejón sin salida. De ahí que surgieran propuestas que intentaron salvar este escollo dando un paso más. Una de ellas (Neumayer, 2003) planteó que una conceptualización operativa para el problema del desarrollo sostenible no había de basarse directamente en la satisfacción de necesidades, sino en la garantía de que el agregado de capitales, que son la materia prima para satisfacerlas, fuera no decreciente con el tiempo. Cuatro son los 
capitales que Neumayer integró en su modelo: el económico, el social, el humano y el natural. Si bien la idea de realizar intercambios entre los tres primeros capitales no suscita excesivas discusiones, no sucede lo mismo con el capital natural. Justamente este punto, es decir qué rol había de jugar el capital natural en el marco amplio del desarrollo sostenible, fue el que dio lugar a las dos principales escuelas de pensamiento sobre la cuestión: se trata de los paradigmas débil y fuerte de sostenibilidad.

Para la sostenibilidad débil, el capital natural no es diferente en absoluto de los otros capitales y puede ser sustituido sin limitación alguna. Por el contrario, los defensores del paradigma de sostenibilidad fuerte argumentan que el capital natural no es de ninguna manera sustituible por otro tipo de capital, sino que es necesario fijar límites absolutos que lo salvaguarden.

Desde nuestro punto de vista, ambas aproximaciones aportan su grano de arena a la cuestión y ayudan a cerrar un marco integrado de análisis de la sostenibilidad global. Desde una perspectiva fuerte, se puede definir la condición necesaria para la sostenibilidad: a saber, que determinados límites resilientes (en términos de depreciación del capital natural) del planeta no se superen bajo ningún concepto, pues si así fuera, la vida en la tierra podría quedar seriamente amenazada. Esta perspectiva eleva asintóticamente el enfoque antropocéntrico de la sostenibilidad hacia el eco-céntrico, pues pone de manifiesto que la salvaguarda del equilibrio ecológico global constituye la condición de posibilidad de todo análisis ulterior sobre el bienestar de los individuos. Por otro lado, desde la perspectiva débil, se insiste en la necesidad de una distribución equitativa de los recursos, hecho que se postula como condición suficiente de la sostenibilidad.

Si el primer problema, por tratarse de establecer límites físicos y ecológicos del planeta, es un problema principalmente ecosistémico, el segundo es esencialmente de carácter ético distributivo, y caeríamos en un nuevo error categorial si confundiéramos los medios (escenarios, modelos, indicadores, etcétera) con el fin. No podemos identificar modelo con realidad, es necesario que todas estas valiosas herramientas aporten contenido al debate ético necesario para abordar la problemática sobre la sostenibilidad global. En esa línea, la sostenibilidad débil habrá de aportar una serie de modelos y métodos de ayuda a la decisión que ayuden en ese proceso ético recursivo de definición y verificación de políticas que permitan caminar hacia un reparto cada vez más equitativo de los capitales, es decir, del bienestar de los individuos, dentro de los límites establecidos por la sostenibilidad fuerte.

Aunque el papel de ambas aproximaciones fuerte y débil queda relacionado con ser condiciones necesaria y suficiente para la sostenibilidad, respectivamente, es interesante ver de qué forma ambas concepciones se interrelacionan y realimentan. Por un lado, ¿qué aporta la sostenibilidad fuerte a la condición suficiente? A nuestro entender podrá aportar, paradójicamente, su orientación eco-céntrica, necesaria para no olvidar que el dúo sistema-entorno, es decir, humanidad-planeta, son indivisibles. Por su parte, la sostenibilidad débil puede 
aportar dos cosas a la condición necesaria: por un lado una aproximación topdown que defina límites a la actividad en sintonía con los límites físicos aportados por el enfoque fuerte (de la termodinámica a la termoeconomía); y por otro la tarea de verificar que la defensa del capital natural crítico, llevada al límite, no deviene en una desvalorización del bienestar de los individuos.

Este es, de forma muy sintética, el problema del desarrollo sostenible que tenemos necesariamente que enfrentar. Se trata, en definitiva, de un problema de dos dimensiones ecológica y humana, fuerte y débil, que se entrelazan formando un sistema único que ha de ser abordado en toda su complejidad, sin caer en la tentación de simplificaciones estériles. Precisamente por eso es tan importante que París y Nueva York, es decir, la COP21 y los ODS, encuentren vías de desarrollo complementarias que nos posibiliten caminar hacia el cambio integral que necesitamos.

\subsection{La Cumbre de París, el cambio climático y el desarrollo humano}

\subsubsection{Un acuerdo universal y voluntario}

La Conferencia de las Partes (COP) de París culminó en lo que muchos han calificado como acuerdo histórico para la lucha contra el cambio climático (United Nations Framework Convention on Climate Change, 2015). Y es cierto que en algunos aspectos lo es. Por primera vez, todos los países del mundo han reconocido la importancia de las emisiones antropogénicas en el cambio climático, y se han comprometido a reducirlas. Por primera vez en la historia de la legislación internacional, 174 países (más la Unión Europea) firmaron un Acuerdo internacional en el primer día del periodo de firma, como fue el 22 de abril, esta vez reunidos en la ciudad de Nueva York, coincidencia afortunada para el hilo conductor de esta historia de dos ciudades. También por primera vez se incluye una aspiración de lograr un calentamiento máximo de $1,5^{\circ} \mathrm{C}$ para fin de siglo. Pero quizá la mayor novedad del acuerdo, y también su principal elemento, alrededor del que se construye gran parte de su arquitectura en lo que tiene que ver con mitigación de emisiones, son las llamadas NDCs, las contribuciones nacionales de carácter voluntario.

Consagrar las NDCs en el acuerdo es su principal logro en materia de mitigación, aunque también su mayor riesgo. Porque, como su propio nombre indica, las contribuciones nacionales, a partir de las que se construye el compromiso global, son voluntarias. De hecho, esto lleva a incoherencias tales como formular una aspiración de 1,5 o $2^{\circ} \mathrm{C}$ mientras que la suma de las NDCs actuales no podrá permitir bajar de 2,6 $6^{\circ} \mathrm{C}$ de calentamiento. En este sentido, la credibilidad del acuerdo es, en opinión de los autores, la de las NDCs y de los esfuerzos adicionales que los países estarán dispuestos a hacer para cubrir la brecha identificada. En tanto que los países o agrupaciones de ellos consigan hacer creíbles sus previsiones de mitigación, así será posible, o no, alcanzar los objetivos de control del calentamiento global establecidos. 
Para tratar de garantizar esta credibilidad, el Acuerdo también incorpora un instrumento novedoso: la necesidad de revisar las NDCs cada 5 años, con ambición creciente, y además en un marco de transparencia para el resto de los países. Esta evaluación y revisión periódica de los objetivos forma parte de los esfuerzos de la agenda internacional por establecer mecanismos de control y seguimiento estrechos, que permitan mejorar progresivamente la ambición de los diferentes instrumentos que se pongan en marcha.

El hecho de que las contribuciones sean voluntarias y universales cambia la dinámica frente a acuerdos previos, en que había obligaciones para unos países y no para otros. Tras París, todos los países están obligados a contribuir, aunque sea de forma voluntaria. Sin embargo, esto no quiere decir que no se establezcan responsabilidades diferenciadas, una idea presente a lo largo de toda la redacción del acuerdo.

\subsubsection{La mitigación para todos}

El Acuerdo establece que los países desarrollados "deberán" (vinculante) seguir liderando el proceso, reduciendo sus emisiones en términos absolutos, mientras que los países en desarrollo "deberían" (más suave) ir asumiendo responsabilidades cada vez mayores en función de sus circunstancias específicas.

En todo caso, el Acuerdo avanza también con respecto a categorías geopolíticas y marcos institucionales ya anticuados, como las utilizadas en el Protocolo de Kioto. Ya no se coloca a los países en dos listas distintas y rígidas, lo que permitirá que vayan asumiendo responsabilidades distintas en función de su nivel de desarrollo.

Además de las responsabilidades diferenciadas, el Acuerdo incluye otras dos provisiones que afectan al reparto de los esfuerzos de mitigación:

- Se deja la puerta abierta a un sistema de intercambio de esfuerzos entre países con carácter voluntario. Aunque no se menciona la palabra mercado, en el fondo es similar, con sus consecuencias positivas (mayor eficiencia) y negativas (riesgo de desigualdad).

- Se crea un mecanismo de mitigación y desarrollo sostenible, cuya gobernanza y reglas deben ser elaboradas y aprobadas en próximas COP. Los términos en los que se define el mecanismo son similares al anterior "Mecanismo de Desarrollo Limpio", aunque se supone que se tratarán de evitar los problemas a los que dio origen éste.

\subsubsection{Los otros pilares}

Por supuesto, el acuerdo también incluye referencias a los otros "pilares de Bali", es decir, a los otros elementos necesarios para responder a todas las demandas y necesidades nacionales: adaptación, transferencia de tecnología, y de- 
forestación. Y también, al igual que para la mitigación, muchos de los detalles de estos temas, salvo quizá en el ámbito de la deforestación, deben desarrollarse en próximas COPs. Aunque el Acuerdo sí define de partida, también en este ámbito, responsabilidades diferenciadas según las capacidades y situación de cada país.

Así, en lo que se refiere a adaptación, el Acuerdo extiende la obligación de los países desarrollados a asistir tanto técnica como financieramente a los países en desarrollo, animando también a otros países a contribuir a este apoyo en la medida de sus posibilidades.

Los esfuerzos de adaptación deben seguir un enfoque transparente y participativo a nivel nacional, teniendo en cuenta cuestiones de género, grupos vulnerables, comunidades y ecosistemas, así como la sabiduría tradicional, el conocimiento propio de las poblaciones indígenas y locales, de forma que la adaptación se pueda integrar en el contexto de las políticas socioeconómicas y ambientales.

Respecto a la transferencia de tecnología, el Acuerdo subraya su importancia y la necesidad de reforzar la cooperación en este aspecto. También recuerda la necesidad de construir capacidad en los países en desarrollo, así como de facilitar el acceso a la financiación, educación, formación y concienciación pública.

\subsubsection{La financiación}

Para financiar todos estos desarrollos, los fondos existentes se mantienen y pasan al servicio del nuevo acuerdo. Y, de nuevo, son los países desarrollados los que deberían liderar la movilización de fondos financieros, siendo aquí muy relevante el papel de los fondos públicos. El Acuerdo establece un objetivo de 100.000 millones anuales de financiación a conseguir para 2020, y más para 2025, para la mitigación y la adaptación. También son estos países los que tienen la responsabilidad de contribuir al desarrollo de las capacidades necesarias en los países menos desarrollados.

Como vemos pues, y en resumen, los países desarrollados deberían contribuir más a la mitigación, deben liderar las aportaciones a la financiación, y deben responsabilizarse de crear las capacidades necesarias para reducir emisiones y adaptarse al cambio climático en los países en desarrollo. En este sentido, y en teoría, el Acuerdo es razonablemente equitativo en el reparto de los esfuerzos. Una debilidad, en nuestra opinión, es que todo esto tiene carácter voluntario y aún por concretar. Pero es que parece difícil que se hubiera podido firmar un acuerdo realmente universal (en lo que se refiere al clima) con compromisos más concretos u obligatorios.

\subsubsection{El desarrollo sostenible}

El Acuerdo sólo tiene tres menciones muy generalistas al desarrollo sostenible: una cuando se refiere al mecanismo de mitigación y desarrollo sostenible, la segunda cuando reconoce la contribución del desarrollo sostenible a la reducción 
del riesgo de pérdidas y daños, y otra en la que se reconoce la importancia de los enfoques que integren mitigación, adaptación, financiación, transferencia de tecnología y construcción de capacidad, "en el contexto del desarrollo sostenible y de erradicación de la pobreza". Esta última es también la única mención a la pobreza en todo el texto. Respecto del aspecto de Acceso Universal a la Energía que hemos elegido como concreción de este artículo, aunque no hay ninguna referencia en el Acuerdo al este tema, sí lo recoge en la Decisión que acompaña el acuerdo como un aspecto de fundamental importancia en los países en desarrollo, en especial los de África, aparejado a un mayor desarrollo de las energías renovables.

\subsection{La Cumbre de Nueva York para el desarrollo y la sostenibilidad}

En Nueva York, en Septiembre de 2015, 150 jefes de Estado y de Gobierno aprobaron en la Cumbre Mundial sobre Desarrollo Sostenible la resolución Transformar nuestro mundo: la Agenda 2030 para el Desarrollo Sostenible (ONU, 2015b), que establece los diecisiete Objetivos de Desarrollo Sostenible (ODS / SDG)) con un triple foco: acabar con la pobreza extrema, luchar contra las desigualdades y la injusticia, y combatir el cambio climático.

\subsubsection{Una sostenibilidad comprehensiva: amplia, diversa y para todos}

La nueva agenda post-2015, aunque heredera de los anteriores Objetivos de Desarrollo del Milenio (ODM / MDG), expande no sólo el número de objetivos de 8 a 17, sino que refleja una concepción más compleja del concepto de desarrollo abordando temas fundamentales en sostenibilidad social, económica y también medioambiental que estaban ausentes en la anterior agenda:

ODS 1. Poner fin a la pobreza en todas sus formas en todo el mundo.

ODS 2. Poner fin al hambre, lograr la seguridad alimentaria y la mejora de la nutrición y promover la agricultura sostenible.

ODS 3. Garantizar una vida sana y promover el bienestar para todos en todas las edades.

ODS 4. Garantizar una educación inclusiva, equitativa y de calidad y promover oportunidades de aprendizaje durante toda la vida para todos.

ODS 5. Lograr la igualdad entre los géneros y empoderar a todas las mujeres y las niñas.

ODS 6. Garantizar la disponibilidad de agua y su gestión sostenible y el saneamiento para todos.

ODS 7. Garantizar el acceso a una energía asequible, segura, sostenible y moderna para todos. 
ODS 8. Promover el crecimiento económico sostenido, inclusivo y sostenible, el empleo pleno y productivo y el trabajo decente para todos.

ODS 9. Construir infraestructuras resilientes, promover la industrialización inclusiva y sostenible y fomentar la innovación.

ODS 10. Reducir la desigualdad en y entre los países.

ODS 11. Lograr que las ciudades y los asentamientos humanos sean inclusivos, seguros, resilientes y sostenibles.

ODS 12. Garantizar modalidades de consumo y producción sostenibles.

ODS 13. Adoptar medidas urgentes para combatir el cambio climático y sus efectos.

ODS 14. Conservar y utilizar en forma sostenible los océanos, los mares y los recursos marinos para el desarrollo sostenible.

ODS 15. Proteger, restablecer y promover el uso sostenible de los ecosistemas terrestres, gestionar los bosques de forma sostenible de los bosques, luchar contra la desertificación, detener e invertir la degradación de las tierras y poner freno a la pérdida de la diversidad biológica.

ODS 16. Promover sociedades pacíficas e inclusivas para el desarrollo sostenible, facilitar el acceso a la justicia para todos y crear instituciones eficaces, responsables e inclusivas a todos los niveles.

ODS 17. Fortalecer los medios de ejecución y revitalizar la Alianza Mundial para el Desarrollo Sostenible.

Nueva York propone, en nuestra opinión, de una agenda no sólo novel sino que mucho más comprehensiva, por un lado profundizando en los objetivos tradicionales del desarrollo, e incorporando no sólo nuevos objetivos de sostenibilidad medioambiental, sino las dimensiones de justicia y prosperidad para todos. Intenta por tanto abarcar el conjunto de problemas de desarrollo y sostenibilidad, como se muestra en la Figura 1, explicitando además que se trata de objetivos tanto para países desarrollados como para los en desarrollo.

Figura 1. ODS vs. ODM según informe de síntesis del Secretario General de Naciones Unidas

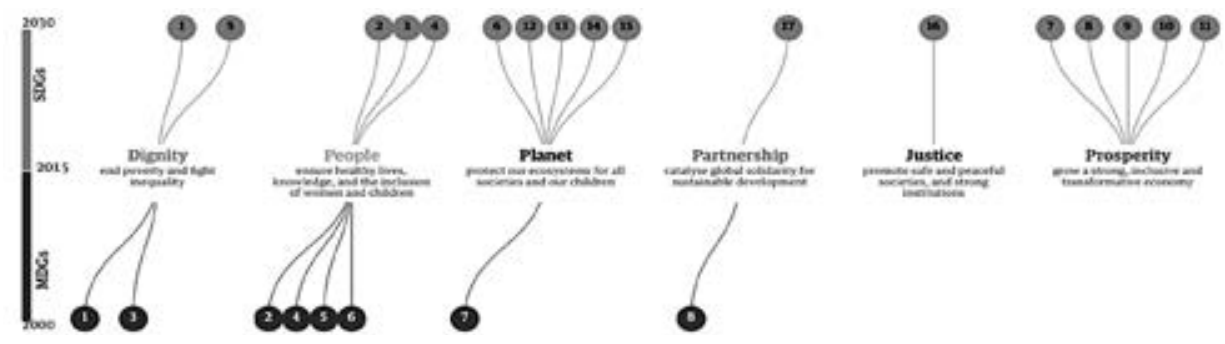

Fuente: United Nations Secretary-General. Ban Ki-moon, 2015.

Infografía: The Guardian Interactive. 
Los primeros cinco objetivos están centrados en la lucha contra la pobreza y por la dignidad de las personas, se sitúan en el centro del proceso de desarrollo (ODS1 a 5) y recogen la mayor parte de la anterior hoja de ruta de desarrollo del milenio.

El segundo punto focal de los ODS es la incorporación transversal en toda la agenda de la idea de sostenibilidad, incorporada en el nombre de los objetivos, entendida tanto como sostenibilidad débil respecto de la interrelación entre los objetivos medioambientales, sociales y económicos, como en su acepción fuerte, en cuanto a la necesidad de respetar límites planetarios absolutos, poniéndose así directamente en confluencia con los objetivos de la Cumbre de París. Pero además de este carácter transversal del cuidado del planeta en la agenda, los objetivos específicos en este área pasan de un solo objetivo (ODM 7) a cinco (ODS 6, $12,13,14$ y 15) cubriendo el acceso al agua, consumo y producción responsables, ecosistemas terrestres y marinos sostenibles y por supuesto, específicamente, la lucha contra el Cambio Climático.

Otra de las grandes novedades de la agenda son los cinco objetivos adicionales relacionados con la prosperidad y la transformación hacia una economía sostenible e inclusiva (ODS 7 a 11), así como la promoción de sociedades justas, seguras y en paz (ODS 16) abordando las interrelaciones de los tres pilares de la sostenibilidad social, medioambiental y económica.

No sólo se trata de una agenda comprehensiva en cuanto a la diversidad y envergadura de los objetivos, sino que además de enfatizar la necesidad radical de mecanismos de redistribución a escala global hacia los países en desarrollo, especialmente hacia los países menos avanzados, los objetivos por primera vez explicitan metas en las que los propios países desarrollados necesitan una profunda transformación que nos conduzcan por una senda segura hacia un desarrollo sostenible e inclusivo global, que tenga en cuenta la magnitud, la interdependencia y la complejidad de los problemas que estamos afrontando, como pone de manifiesto Mataix (Alonso et al., 2013).

\subsubsection{Una agenda participativa}

Es además una agenda que ha incorporado desde el inicio la participación de muy diferentes actores, no sólo a través de los procesos consultivos en cada país, como el realizado en España (Secretaría General de Cooperación Internacional para el Desarrollo, 2014) con la presencia de universidades (incluyendo ponencias de profesores e investigadores de la Universidad Pontificia Comillas ICAI-ICADE), ONG, empresas, sindicatos y otras instituciones; sino que todos estos actores han podido enviar sus posicionamientos frente a los diferentes documentos parciales que se han discutido en las diferentes fases del proceso de negociación en el foro de Naciones Unidas. 
Pero también el proceso ha permitido en esta ocasión la participación directa de los ciudadanos a través de encuestas masivas (data.myworld2015.org) que han informado el peso de los diferentes objetivos por países, edad, y situación de desarrollo, evidenciando cómo algunos grandes temas que en la agenda del milenio no estaban presentes, cobraban ahora una gran importancia, como es el caso del acceso universal a la energía para la población de los países menos avanzados, la protección contra el crimen y la violencia, la industrialización, la desigualdad de ingresos, la sostenibilidad de las ciudades, por mencionar algunos.

\subsubsection{Una llamada a la acción colectiva, progresiva y transformadora}

Se trata de una agenda para la acción donde los 17 ODS se desglosan en 169 metas, que a su vez van a ser objeto de seguimiento y examen a través de un conjunto de indicadores mundiales (unstats.un.org/sdgs) que pretende mejorar y globalizar los mecanismos de control de la consecución de los objetivos, no sólo individualmente sino también atendiendo a las interrelaciones entre unos y otros, definiendo progresivamente indicadores multi-propósito.

Es precisamente en las cuestiones de seguimiento y cumplimiento de las metas donde los ODS tienen uno de sus mayores retos. Según el informe Projecting Progress: reaching the SDGs by 2030 del Overseas Development Institute (Nicolai, Hoy, Berliner, y Aedy, 2015), que analiza 17 metas, una por cada ODS, la situación sería la siguiente (ver Figura 2):

- Solamente tres estarían en vías de solución teniendo en cuenta los acuerdos alcanzados hasta la fecha: Meta 1.1 Erradicar la pobreza extrema; Meta 8.1 Crecimiento económico en los Países Menos Avanzados y Meta 15.2 Frenar la deforestación.

- Una mayoría de metas requerirían multiplicar los esfuerzos actuales para poder lograrse en el horizonte 2030: Metas 3.1 Reducir la mortalidad en el parto; 4.1 Educación secundaria universal; 16.1 Reducir las muertes violentas; 17.1 Movilizar los recursos domésticos; 2.1 Erradicar el hambre; 6.2 Acceso universal al saneamiento; 7.1 Acceso universal a la electricidad; 5.3 Erradicar el matrimonio infantil y 9.2 Industrialización de los países menos avanzados.

- Hay cinco objetivos en los que tanto los países en desarrollo como aquellos que llamamos desarrollados tendrían que cambiar de rumbo no sólo para poder conseguir para 2030 los objetivos planteados, sino para no empeorar en dichas metas siguiendo con sus actuales políticas: Meta 10.1 Reducir las desigualdades económicas; Meta 11.1 Reducir el chabolismo; Meta 12.5 Reducir los residuos; Meta 13.2 Combatir el cambio climático y Meta 14.2 Proteger el ecosistema marino. 
Conseguir estas metas requiere un cambio profundo del modelo productivo existente, lo que apareja la necesidad tanto de compromiso político como de creatividad e innovación, junto a patrones responsables de consumo.

\section{Figura 2. Proyección del progreso en la consecución de 17 metas pertenecientes a los ODS}

\section{SDG SCORECARD 2030 RESULTS}

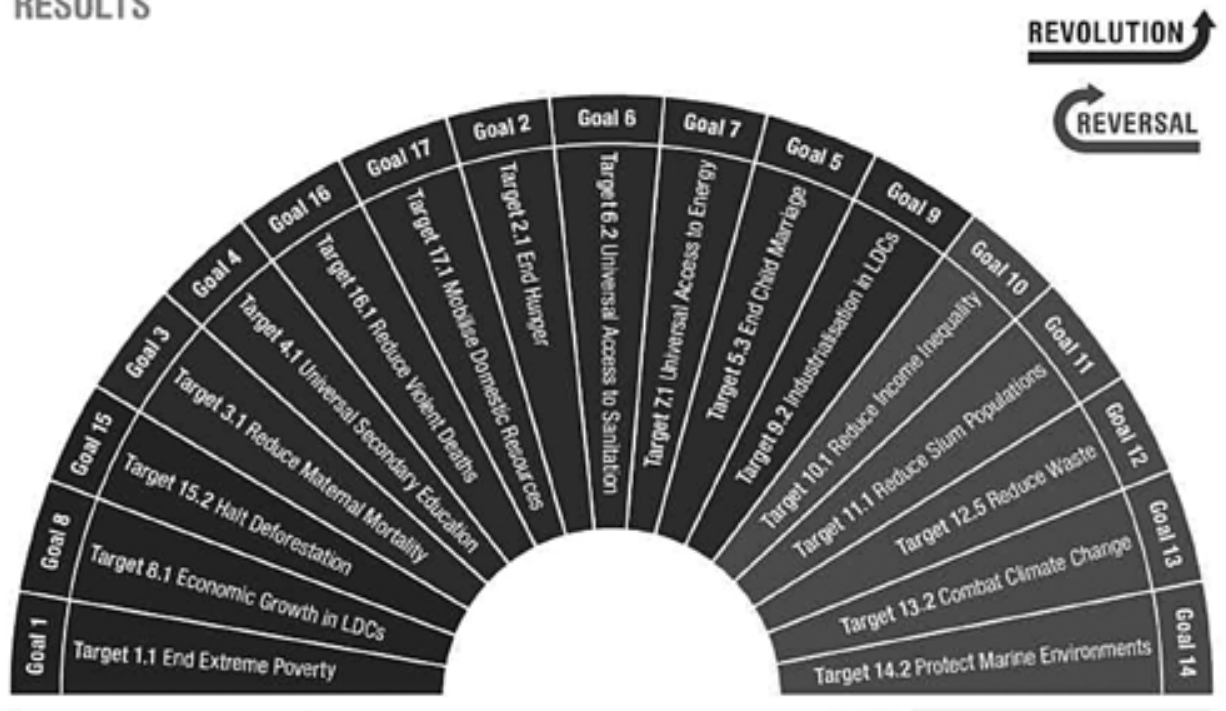

Fuente: ODI Projecting Progress: reaching the SDGs by 2030 (Nicolai, Hoy, Berliner, \& Aedy, 2015).

\subsubsection{La financiación del desarrollo sostenible}

Otro de los grandes desafíos que enfrenta esta Agenda está en los mecanismos de financiación. Tras la III Conferencia Internacional sobre la Financiación para el Desarrollo: Agenda de Acción de Addis Abeba (ONU, 2015a) resulta evidente que conseguir los 17 ODS en sus 169 Metas requerirá un esfuerzo multiplicado, respecto de los presentes compromisos firmados en Nueva York. Es necesario compartir los esfuerzos y beneficios de manera equitativa entre los países en desarrollo y los países desarrollados, articulando tanto mecanismos de inversión pública como de capital privado, aprovechando los mecanismos de mercado, especialmente aquellos que favorecen la inclusión de la población desfavorecida en 
la base de la pirámide, allí donde una buena regulación, innovación en tecnologías y modelos de negocio y un régimen de incentivos adecuados permita escalar los esfuerzos aprovechando las potencialidades de todos.

\section{YENDO Y VINIENDO ENTRE LAS DOS CIUDADES}

\subsection{Un equilibrio sostenible entre lo social, lo medioambiental y lo económico}

El relato de nuestras dos ciudades en 2015 hunde sus raíces en un mundo global, con consciencia de ser finito e interdependiente, en una situación de profunda emergencia social y medioambiental y que además evoluciona muy rápidamente. Aunque iniciamos este artículo citando el inicio de Historia de dos ciudades, que establece un paralelismo entre el mundo actual y el pasado, en nuestra opinión hoy, este nuevo mundo es en realidad distinto a aquel en que se construyó nuestro sistema de relaciones internacionales tras la segunda guerra mundial, distinto también en cuanto a la necesidad de colaboración y reparto de cargas y beneficios entre estados y distinto ad intra de los propios estados nación. Distintos también tendrán que ser los paradigmas económicos, de desarrollo, sociales y medioambientales que conformen este nuevo mundo. Es necesario renovar, innovar y en ocasiones dar la vuelta a estos marcos de pensamiento si queremos afrontar estos nuevos riesgos para generaciones presentes y futuras, en una medida y dimensión acorde con la magnitud de los problemas que enfrentamos.

En este nuevo entorno global, la extrema división y desigualdad entre el Norte y el Sur en el mundo industrial y post-industrial del siglo XX ha dado paso a fenómenos más complejos donde la desigualdad crece más rápidamente en el interior de los países. Donde mientras las élites incluidas en la globalización acercan sus posiciones, grandes bolsas de población tanto en el mundo en desarrollo como en el desarrollado quedan excluidas de los beneficios de este gran proceso global. De los dos grandes bloques hegemónicos que articularon las segunda mitad del pasado siglo hemos pasado a un mundo multipolar. De los proyectos nacionales de desarrollo económico como herramienta de trabajo hemos pasado a la necesidad de plantear estrategias globales, regionales, nacionales y también locales diferenciadas. También el perfil de la pobreza en este nuevo mundo es distinto, pasando desde el ámbito rural a convertirse en un fenómeno creciente en los suburbios de las grandes capitales, y no sólo de nuevo en los países menos avanzados o en desarrollo, sino también en lo que llamamos el Norte.

En este mundo interdependiente la sostenibilidad se plantea como un tema global central, aparejando lo económico, lo medioambiental y lo social. Ampliando el conocido paradigma sobre la necesidad de encauzar nuestro sistema dentro de los lí- 
mites de un espacio seguro para la humanidad (Rockström et al., 2009) en equilibrio con el medioambiente, Oxfam propone la necesidad de encontrar un espacio seguro y justo para la humanidad (Raworth, 2012), que respeta esos límites planetarios permitiendo un desarrollo económico sostenible e inclusivo sobre unas bases sociales esenciales en torno al acceso a trabajo, agua, comida, salud, energía, educación, ingresos, capacidad de resiliencia, participación social, equidad social y de género.

\section{Figura 3. Espacio seguro y justo para la humanidad entre los límites planetarios y las necesidades de desarrollo}

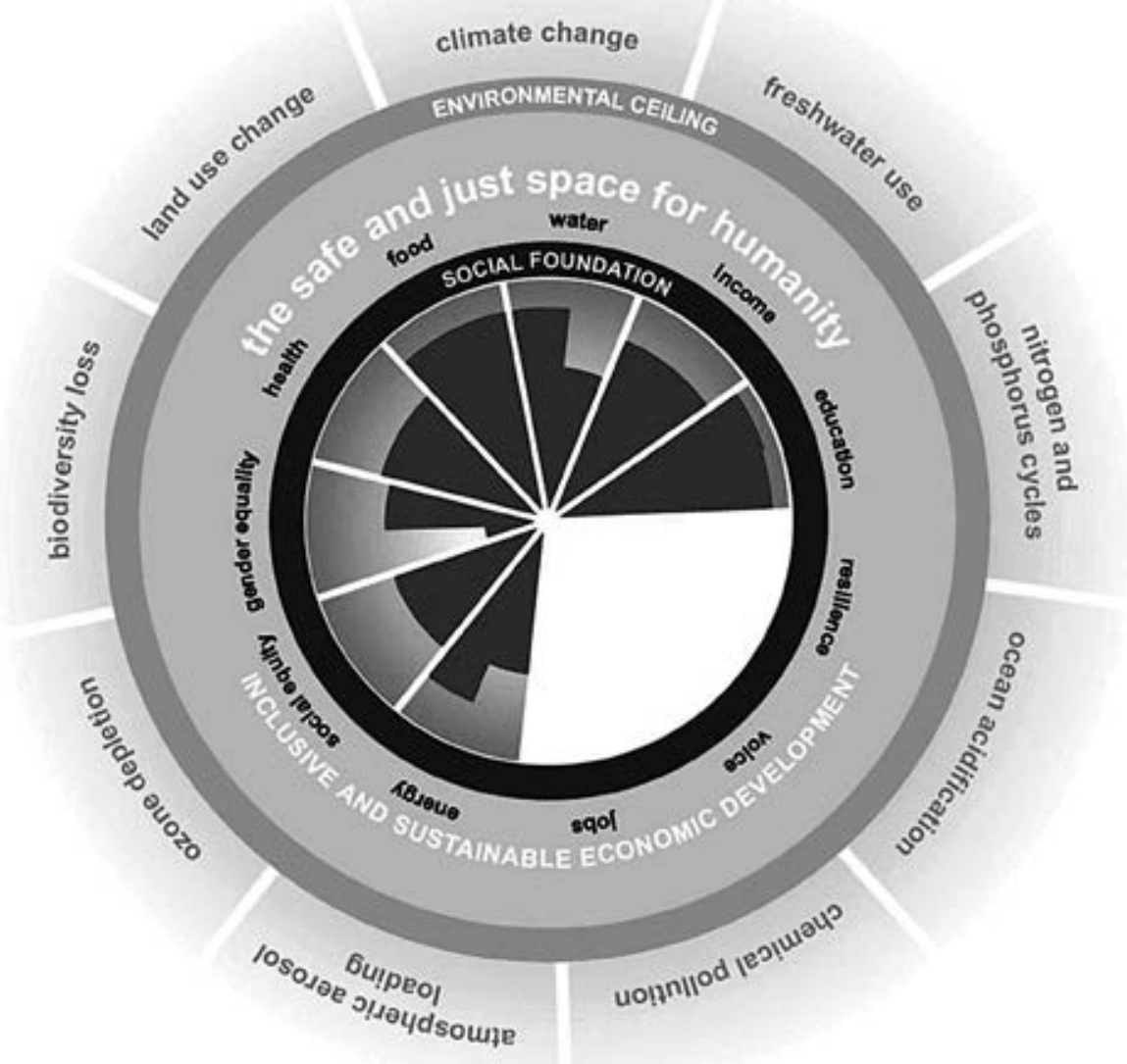

Fuente: Oxfam (Raworth, 2012).

Este difícil equilibrio entre lo social, lo económico y lo medioambiental requiere de un nuevo marco de valores compartidos (Porter y Kramer, 2011), en 
el que empresas, gobiernos, instituciones, sociedad civil y los propios individuos puedan impulsar los cambios y las innovaciones necesarias para promover un desarrollo inclusivo y sostenible de forma valiente y decidida, al tiempo que se respetan con prudencia los límites duros y los equilibrios con el planeta, de forma que el ecosistema sobre el que se fundamenta la actividad humana en este nuevo mundo mantenga un necesario equilibrio para todos.

Dada la limitada extensión de este artículo, presentamos a continuación el objetivo de Acceso Universal a la Energía (ODS7 Meta 1.1) como un aspecto concreto, pero fundamental, de la interrelación entre lo social, lo económico y la lucha contra el cambio climático, en la confluencia entre las dos agendas.

\subsection{El cambio climático: ¿una amenaza al desarrollo humano?}

"Los peligros conexos al clima afectan a las vidas de las personas pobres directamente a través de impactos en los medios de subsistencia, reducciones en los rendimientos de los cultivos o destrucción de hogares e, indirectamente, a través de, por ejemplo, aumentos en los precios de los alimentos y en inseguridad alimentaria" (IPCC Grupo de Trabajo II, 2014).

La Cumbre de París se asienta en las conclusiones del quinto informe de evaluación del Grupo Intergubernamental de Expertos sobre el Cambio Climático del que hemos tomado el párrafo anterior, y que es inequívoco en dos afirmaciones fundamentales:

1. El cambio climático plantea riesgos para los sistemas humanos y naturales.

2. El cambio climático y el desarrollo están intrínsecamente interconectados.

El cambio climático es una fuente adicional de vulnerabilidad que, añadida a situaciones de riesgo ya existentes, puede exacerbar la desigualdad y crear nuevos focos de pobreza, tanto en los países desarrollados como en desarrollo. El Banco Mundial (Hallegatte et al., 2016) estima que los efectos del cambio climático impedirán a muchas personas salir del círculo vicioso la exclusión. Sin un desarrollo rápido, inclusivo e inteligente, es posible que antes de 2030 se incremente en otros $100 \mathrm{mi}$ llones el número de personas en situación de pobreza debida a procesos climáticos, como por ejemplo de la pérdida de cosechas (debida a unas menores precipitaciones), la pérdida de infraestructuras e incremento en los precios de los alimentos (a causa de fenómenos meteorológicos extremos, que afectarán especialmente a aquellos hogares pobres en donde el consumo de alimentos supone un porcentaje alto del gasto total del hogar), la mayor incidencia de diversas enfermedades tras olas de calor e inundaciones (como el paludismo o las enfermedades intestinales debidas a la dificultad de acceso a agua potable), entre otros fenómenos que se incrementarían. 
Así, muchos países en desarrollo identifican objetivos de desarrollo como el acceso al agua (desarrollo de los recursos hídricos) y la seguridad alimentaria (mejora de las cosechas) dentro de las prioridades de sus Programas Nacionales de Acción de Adaptación al Cambio Climático. La disponibilidad de recursos energéticos se ve también afectada, especialmente en los países con alta dependencia a la biomasa y la hidroelectricidad como fuentes de energía, o con instalaciones energéticas en zonas expuestas a las inundaciones (Labriet, Fiebig, y Labrousse, 2015). Por el contrario, la energía solar o eólica, además de favorecer un desarrollo energético bajo en carbono y adaptado a las zonas aisladas, ofrece una mejor adaptación posible al cambio climático gracias a la vida útil relativamente corta y portabilidad de los equipos, cuyo cambio permite la instalación de nuevos equipos adaptados a las nuevas condiciones climáticas en caso necesario. Reducir la dependencia de los países pobres respecto del uso tradicional de la biomasa, diversificar las fuentes y mejorar la eficiencia energética (consumir menos sin reducir los servicios energéticos) son los pillares fundamentales de una estrategia energética resiliente al cambio climático.

Las comunidades pobres se ven más afectadas por los efectos del cambio climático dado sus recursos limitados para adaptarse y su alta dependencia a los recursos naturales para su subsistencia (agricultura, pesca, ganadería). En diferentes clasificaciones de los países respecto de su resiliencia medioambiental (Climate Change and Environmental Risk Analytics de Verisk Maplecroft, ND-GAIN Country Index, Food Insecurity and Climate Change Vulnerability Index), los países en desarrollo aparecen como los más vulnerables al cambio climático. En otras palabras, aunque los 17 objetivos de desarrollo sostenible de la Agenda 2030 para el desarrollo sostenible de las Naciones Unidas incluyan un objetivo específico sobre el cambio climático (ODS-13), muchos de los otros 16 se ven directamente afectados por los impactos del cambio climático, haciendo del cambio climático y el desarrollo sostenible "dos caras de una misma moneda" a caballo entre París y Nueva York.

\subsection{La satisfacción de necesidades alimentarias y energéticas: ¿una amenaza al clima?}

\subsubsection{La energía, pillar del desarrollo}

Un aspecto de la interrelación entre la agenda energética explicitada en el ODS7 y la Agenda de París es el acceso a la energía. Los servicios energéticos están presentes en una mayoría de las actividades humanas modernas. A través de la iluminación, de la cocción de los alimentos, del calentamiento de los hogares y del agua, del frio para almacenar alimentos y medicamentos, de los servicios de transporte, de las comunicaciones, de los procesos productivos, los servicios ener- 
géticos son clave para la educación, la salud, la generación de ingresos, en otras palabras, el bienestar de las personas, el desarrollo y la lucha contra la pobreza. La gran mayoría de los actores de la cooperación internacional reconocen ahora la relación inextricable entre la energía y el desarrollo sostenible. De ahí nació, en 2011, la iniciativa de las Naciones Unidas "Energía Sostenible para Todos" (SE4ALL Sustainable Energy for all) a la cual se han asociado los gobiernos, el sector privado y la sociedad civil para lograr tres objetivos importantes tanto para países en desarrollo como desarrollados, en horizonte 2030:

1. Garantizar el acceso universal a servicios energéticos modernos, incluyendo los servicios eléctricos.

2. Duplicar el ratio de mejora en la eficiencia energética.

3. Duplicar el uso de la energía renovable a nivel mundial (equivalente a alcanzar el 30\%).

Aunque el cambio climático no se mencione de manera explícita en los objetivos de SE4LL, cada objetivo está ligado a las causas y consecuencias del cambio climático, como la disponibilidad de los recursos energéticos y las emisiones asociadas con su uso. El ahorro energético, la eficiencia y las energías renovables son esenciales para afrontar el reto del cambio climático, además de constituir opciones más adecuadas para contribuir al acceso a servicios energéticos de todas las comunidades, incluyendo las más pobres y las que están localizadas en zonas rurales aisladas mas adaptadas a sistemas de suministro eléctrico descentralizados.

\subsubsection{Las consecuencias sobre las emisiones}

Respecto del acceso universal a la energía, el desarrollo tecnológico en los países desarrollados y en desarrollo debe abordar los desafíos del Cambio Climático conjuntamente con la satisfacción de las necesidades de acceso de su población y con la lucha contra la pobreza energética. Comparado con el Escenario de Nuevas Políticas (donde se considera que las políticas ya anunciadas por los gobiernos se implementan realmente) de la Agencia Internacional de la Energía (AIE) de lograr el acceso universal a la energía en 2030 incrementaría la generación global de energía eléctrica en un 2,5\%. Casi el 70\% de esta generación seria de origen renovable. En consecuencia, la demanda de combustibles fósiles crecería en un $0.8 \%$ y las emisiones de carbono en un 0,7\%, siendo ambas figuras irrelevantes en comparación con las principales preocupaciones del Cambio Climático (IEA, 2011; IPCC WGIII, 2014). Este bajo nivel de emisiones se debe principalmente al bajo nivel de consumo per cápita y a la alta proporción de renovables que el Escenario de Nuevas Políticas supone. 
Por otro lado, los escenarios "business as usual" de la AIE consideran una proporción mucho más alta de generación diesel en la electrificación fuera de red, en comparación con el Escenario de Nuevas Políticas, lo cual, según los cálculos de los autores, podría incrementar las emisiones hasta la cifra de 1,5\%. El crecimiento posterior de los niveles de consumo a cifras en torno a los $2.000 \mathrm{kWh}$ por persona y año, asociados a posibilitar procesos de desarrollo y crecimiento económico adecuados, resultaría en un escenario posible donde las emisiones crecerían hasta el 3,6\%.

Sin embargo, en nuestra opinión, el bajo consumo supuesto para los nuevos clientes subestima el impacto posible del acceso a la energía en el Cambio Climático si no se toman medidas políticas fuertes a favor del desarrollo de las energías renovables y de la eficiencia energética a gran escala. En efecto, resulta a la vez injusto, en una perspectiva de desarrollo humano, y difícil de creer que en los períodos de tiempo considerados por los análisis de Cambio Climático habituales (2050 o para finales del presente siglo) el consumo de esta población se mantenga en estos bajos niveles (Brazilian y Pielke, 2013; Wolfram, Shelef, y Getler, 2012). Resulta evidente que la elección de una hoja de ruta adecuada hacia el Acceso Universal desde el primer momento, define una tendencia apropiada para el crecimiento de las necesidades y del consumo energético, especialmente si se consideran usos productivos que requieren de mayores potencias. De manera parecida a nuestras dos ciudades, las energías renovables y la eficiencia energética son dos hermanas imprescindibles a un desarrollo bajo en carbono.

\subsubsection{El caso de la energía para cocinar}

Otro aspecto importante que relaciona el desarrollo sostenible social y medioambiental con la agenda climática está en la necesidad, para cerca de 3000 millones de personas en el mundo, de abandonar formas de cocina tradicional basadas en el "fuego sobre tres piedras". Uno de sus principales productos, las partículas de carbono negro contenidas en el humo del hogar, también llamadas hollín o negro de carbón, no sólo tienen efectos nefastos sobre la salud de las personas, sino que también contribuyen significativamente al cambio climático, absorbiendo radiaciones y reduciendo la reflexión de las radiaciones (el albedo) de la nieve y el hielo, como detallamos a continuación.

El hollín es emitido por la combustión incompleta de combustibles fósiles y de biocombustibles, incluyendo la biomasa (incendios agrícolas y forestales y usos para cocinar y calentar). Además, el carbono negro siendo parte de los contaminantes climáticos de vida corta que permanecen en el aire solamente algunos días (en comparación con los 100 años del $\mathrm{CO}_{2}$ ), las opciones de mitigación de estas emisiones tienen la ventaja de frenar el cambio climático a corto plazo. 
En los países en desarrollo la mayoría de personas todavía cocinan y calientan sus hogares con fuegos abiertos y cocinas en los que queman biomasa, principalmente leña, y carbón, con importantes impactos negativos:

- Se estima que más de 4 millones de personas mueren de manera prematura cada año (OMS, 2015) por enfermedades atribuibles a la contaminación del aire de los hogares, como consecuencia del uso de combustibles sólidos para cocinar (neumonía, accidente cerebro vascular, cáncer y otras enfermedades de pulmón).

- Se dedican más de 2 horas diarias a la recogida de la leña en la naturaleza, actividad físicamente dura por el peso de la leña, realizada en la mayoría de casos por mujeres y niños, tiempo detraído de otras actividades posibles como educación, formación profesional, actividades productivas, o también juego y descanso. Este tiempo tiene un valor económico, aunque poco valorizado de manera directa en muchos casos. Cuando la leña se compra, su uso representa pérdidas económicas asociadas por la baja eficiencia de su quema en los fuegos abiertos y en las estufas convencionales (EsF, 2012).

- La combustión ineficaz de la leña se añade a las otras causas de deforestación, como el cambio en el uso de suelos por motivos agrícolas u otros. La pérdida de cobertura forestal significa también la pérdida de sumideros de carbono (árboles y suelos), contribuyendo también así al cambio climático.

El efecto neto de la combustión incompleta de combustibles sobre el cambio climático es difícil de precisar, debido a los posibles efectos de compensación por otras partículas emitidas al mismo tiempo (Lee, Chandler, Lazarus, y Johnson, 2013). No es fácil tampoco evaluar con certidumbre la cantidad de leña que se usa para cocinar y que no procede de masas forestales no replantadas, parámetro importante de las metodologías de cálculo del impacto del uso de la leña sobre el cambio climático (Bailis, Drigo, Ghilardi, y Masera, 2015). Sin embargo, ofrecer un acceso universal a tecnologías y fuentes de energía más eficientes y/o limpias para cocinar (estufas mejoradas con chimenea, biogás, gas líquido de petróleo, entre otros) en lugar del uso ineficiente de la leña resultan en beneficios múltiples inmediatos y locales en las zonas donde se adoptan las medidas, lo que motiva y justifica su puesta en marcha en cualquier caso: mejorada de la calidad del aire local y la salud (ODS-3), de las condiciones de vida y de la económica familiar (ODS-1), reducción de las desigualdades de género (ODS-5), de la deforestación (ODS-15), entre otros.

Los proyectos y programas de promoción del acceso universal a tecnologías modernas y eficientes de cocina se están multiplicando, con el apoyo de distintas fuentes de financiación que en muchos casos valoran no solo el impacto climático sino también otras dimensiones del proyecto relativas a la sostenibilidad econó- 
mica y social. En este sentido, estos proyectos y programas pueden obtener bonos de carbono en el mercado oficial del $\mathrm{CO}_{2}$, gracias a los Mecanismos de Desarrollo Limpio (MDL) de las Naciones Unidas, o en los mercados voluntarios acreditados por sellos de calidad, como el Gold Standard. Dada la elevada oferta de bonos de carbono y su limitada demanda, el valor de los bonos de carbono, alrededor de 5 EUR por tonelada de $\mathrm{CO}_{2}$, no alcanzan los niveles suficientes para que estos proyectos y programas sean realmente atractivos. Sin embargo, el valor del bono podría volver a subir en el futuro a la luz del presente Acuerdo de Paris. Otras fuentes de financiación para los proyectos de servicios energéticos para cocinar también reforzadas por el Acuerdo de Paris son las Acciones de mitigación apropiadas a cada país (NAMA - Nationally Appropriate Mitigation Action) y los planes de Contribución Prevista y Determinada a Nivel Nacional (NDC - Nationally Determined Contribution) propuestos por los países en desarrollo. Por ejemplo, las NAMAs de Uganda y de México incluyen acciones específicas sobre las estufas mejoradas de leña, y se esperan más NAMAs similares en el futuro.

\subsubsection{Los usos agrícolas, ganaderos y energéticos de la tierra}

Uno de los puntos calientes entre las agendas de desarrollo y climática está en la desforestación, la pérdida de los sumideros de carbono por la presión productiva. Los ODS incorporan en los objetivos medioambientales la necesidad de frenar la desforestación, encontrar modelos de agricultura sostenibles, patrones de consumo adecuados y buscar alternativas renovables a nuestro modelo energético.

El uso de la tierra es, a juicio de los autores, una de los aspectos clave donde es necesario encontrar soluciones innovadoras. Una ética de la sostenibilidad apropiada es un fundamental para garantizar la erradicación del hambre, promover una alimentación variada y saludable, el difícil equilibrio entre garantizar la seguridad alimenticia de las comunidades rurales, promover la rentabilidad y productividad de los cultivos evitando caer en una malsana dependencia la orientación a las exportaciones o los monocultivos, adecuar la regulación para mitigar el poder de mercado sobre la compra y uso de la tierra de los oligopolios de distribución alimenticia, y promover criterios de comercio justo y valores compartidos en las cadenas comerciales, que garanticen la sostenibilidad no sólo económica sino también social y medioambiental tanto del uso de la tierra como del modelo productivo agrícola y ganadero

Desde el punto de vista energético, los riesgos medioambientales y sociales de las grandes infraestructuras hidroeléctricas, por ejemplo en la Amazonía, o por ejemplo la sostenibilidad de los biocombustibles y el cultivo de los mismos se encuentran con un dilema en cuanto al Indirect Land Usage Change (ILUC). Analizar estas cuestiones en profundidad excede el ámbito de este artículo, aunque 
podemos apuntar que "a primera vista, los biocombustibles tienen un impacto adicional al que supone su uso directo: cuando se cultivan biocombustibles, esto puede ser que se haga en tierras anteriormente de bosque, y al cortar el bosque para cultivar, se emite (o se deja de capturar) CO2. Lo mismo pasa con los alimentos: si cultivamos biocombustibles en tierras en las que previamente se cultivaba alimento, habrá menos oferta de estos, y por tanto subirá su precio" (Linares, 2014). Hay muchas interacciones que hacen el problema más complicado, dado que el uso de biocombustibles supone menos ozono y ello aumenta por ejemplo la productividad de las cosechas. Resulta muy difícil estimar estos impactos y por tanto el ILUC dependerá de muchos factores, y aislar de entre ellos el efecto de los biocombustibles o del uso de la tierra.

\section{LA INNOVACIÓN PARA EL DESARROLLO SOSTENIBLE: EN EL CORAZÓN DE LAS DOS CIUDADES}

En esta historia de dos ciudades, ¿puede jugar la innovación un papel relevante? A juzgar por el protagonismo que ha cobrado el término en las propias agendas, especialmente en la de los ODS como hemos visto anteriormente, la respuesta parece ser un claro y rotundo "sî". Ante el reconocimiento generalizado de que las soluciones tecnológicas y los diseños institucionales actuales no bastan para dar respuesta a la urgencia y magnitud de los retos a los que nos enfrentamos, la innovación no sólo puede si no que debe jugar un papel clave en la lucha contra el cambio climático y la consecución de los ODS (Buluswar, Friedman, Mehta, Mitra, y Sathre, 2014).

En esta sección detallamos qué han dicho y qué no han dicho los acuerdos de París y Nueva York sobre innovación, valorando positivamente los avances en el discurso de las agendas pero también señalando desde un punto de vista crítico alguna de sus carencias o ambigüedades. Empezamos viendo cómo aluden a la innovación los acuerdos alcanzados.

\subsection{La innovación en las dos Agendas}

El acuerdo resultante de la COP21 de París recoge un epígrafe (dentro del artículo 10) centrado de lleno en la apuesta por la innovación. Dice así: "Para dar una respuesta eficaz y a largo plazo al cambio climático y promover el crecimiento económico y el desarrollo sostenible es indispensable posibilitar, alentar y acelerar la innovación. Este esfuerzo será respaldado como corresponda, entre otros por el Mecanismo Tecnológico y, con medios financieros, por el Mecanismo Financiero de la Convención, a fin de impulsar los enfoques colaborativos en la labor de investigación y desarrollo y de facilitar el acceso de las Partes que son países en desarrollo a la tecnología, en particular en las primeras etapas del ciclo tecnológico". 
Por su parte, en la agenda de desarrollo post-2015 aprobada en Nueva York, el término "innovación" aparece hasta 25 veces en el texto, y se cuela como parte del noveno objetivo: "construir infraestructuras resilientes, promover la industrialización inclusiva y sostenible y fomentar la innovación" (Naciones Unidas, 2015). Además, el texto resalta el papel de la innovación como "medio de implementación" transversal a todos los objetivos.

En los textos de ambos acuerdos vemos cómo convive la visión de la innovación como medio para afrontar los retos del desarrollo y como fuente de oportunidades económicas. El acuerdo de París habla explícitamente de "promover el crecimiento económico y el desarrollo sostenible", y en la redacción de los ODS aparece la innovación como medio para "avanzar hacia modalidades de consumo y producción más sostenibles" y para "lograr niveles más elevados de productividad económica".

\subsection{Una visión colaborativa de la innovación para la sostenibilidad}

Ciertamente, el discurso predominante sobre la innovación en los últimos años ha estado muy vinculado a la promoción de la actividad económica: la innovación se presenta como una fuente de mejora de la productividad, de empleo y de riqueza. Esta perspectiva, si se acepta sin matices, puede llevarnos a suponer que la innovación es deseable en sí misma, como motor insustituible del crecimiento económico, interpretando a su vez como fuente de bienestar.

Sin embargo, no debiéramos olvidar que la innovación nos lleva a transformar nuestros sistemas sociotecnológicos en una determinada dirección. Una aproximación responsable a la hora de decidir qué tipo de innovación queremos fomentar debiera llevarnos a preguntarnos: ¿para qué queremos innovar? ¿Queremos innovar para el crecimiento económico, para la conservación del planeta, para la mejora del bienestar humano,...?

Las propias agendas apuntan a un horizonte: el de la sostenibilidad, como concepto integrador que aúna progreso económico, ambiental y social. Si aceptamos que la sostenibilidad nos marca el horizonte hacia el que queremos caminar, entonces debiéramos apostar por innovaciones que nos permitan avanzar en esa dirección, y -valientemente- rechazar aquella que nos desvía.

Así por ejemplo, desde este punto de vista, no podríamos considerar deseable la innovación en fracking para extraer recursos fósiles hasta ahora inaccesibles, porque iría en contra de la consecución de nuestros objetivos climáticos. De la misma manera, no sería tampoco deseable introducir de forma masiva e indiscriminada biocombustibles de origen agrícola como forma de reducción de emisiones si hacerlo entrase en conflicto con atender necesidades básicas de alimentación de la población.

El poner la sostenibilidad como horizonte debiera también invitarnos a cuestionar los planteamientos regionalistas y cortoplacistas que subyacen a muchos de 
nuestros esfuerzos actuales de innovación. Necesitamos incorporar las perspectivas global y de largo plazo en nuestras decisiones.

Esto es en parte requisito y en parte oportunidad. Requisito por el carácter global y de largo alcance de muchos de los retos a los que nos enfrentamos, siendo el cambio climático el ejemplo más paradigmático. Oportunidad porque existe un enorme potencial global de creatividad e ingenio para encontrar soluciones sostenibles, como nos demuestran multitud de casos de éxito de innovación para el desarrollo (por ejemplo, en el campo de la electrificación de zonas rurales aisladas).

En esta línea, poner la sostenibilidad en el punto de mira de la innovación nos invita también a repensar el énfasis en la competitividad que tienen actualmente muchos esfuerzos innovadores, para dar cabida a enfoques más colaborativos e inclusivos.

Afortunadamente, los acuerdos de París y Nueva York sí apuntan a una visión colaborativa de la innovación, aunque no con demasiada concreción. El acuerdo de París habla de "impulsar los enfoques colaborativos en la labor de investigación y desarrollo" y de facilitar el acceso de los países en desarrollo a la tecnología, mientras que el acuerdo de NY pone sobre la mesa un mecanismo de facilitación de la tecnología basado en un "marco de colaboración múltiple entre los Estados Miembros, la sociedad civil, el sector privado, la comunidad científica, las entidades de las Naciones Unidas y otras partes interesadas".

En definitiva, hemos visto como los acuerdos de París y Nueva York otorgan a la innovación un papel muy relevante para el avance de sus agendas, y suponen un avance positivo (aunque un tanto tibio) en el discurso para una innovación responsable y colaborativa que nos permita avanzar en la dirección de la sostenibilidad.

\section{CONCLUSIONES}

Al contrario de lo que reza el inicio de la Historia de dos ciudades de Dickens, parece demostrado que hay realidades y fenómenos nuevos a los que se enfrenta la humanidad que hacen de nuestra época actual algo no tan parecido a las épocas pasadas. Las hojas de ruta que marcan las agendas de París y Nueva York son cartas de navegación para este nuevo mundo, complementarias e interrelacionadas, que plantean importantes certezas y no pocas incógnitas, algunas de las cuales hemos tratado de apuntar en este artículo:

- Ambas agendas reflejan consensos no sólo científicos, sino políticos, económicos y también culturales, respecto de un nuevo modelo de desarrollo global, complejo y multidimensional. Suponen así un marco de referencia para la acción a corto, medio y largo plazo. 
- Siendo dos marcos globales, implican cambios al interior de cada país, tanto de ámbito nacional como regional y local, suponiendo también una necesidad de cambio cultural para los propios individuos.

- Los compromisos alcanzados en ambas agendas por primera vez obligan tanto a países desarrollados como en desarrollo, según sean sus capacidades, necesidades y voluntades, arbitrándose mecanismos de coordinación y balance entre unos y otros, de naturaleza diversa, revisables y flexibles.

- Es en estos balances entre obligaciones, esfuerzos y capacidades, donde la voluntariedad de los compromisos y la falta de mecanismos suficientemente ambiciosos y vinculantes suponen un mayor riesgo para el logro de los objetivos de París y Nueva York.

- Al tiempo que la agenda climática incorpora las necesidades de los países en desarrollo y los valores de equidad y erradicación de la pobreza, la agenda de desarrollo se amplia con una vocación comprehensiva, y su visión del desarrollo incorpora de raíz la dimensión de sostenibilidad, poniendo en el centro al ser humano y su actividad, al tiempo que se respetan los límites planetarios (sostenibilidad fuerte) que marcan puntos de no retorno, en especial el de alcanzar un incremento global de temperatura inferior a $1.5^{\circ}$, y se mantienen los equilibrios con el medio natural (sostenibilidad débil).

- Así el paradigma del desarrollo sostenible entre ambas agendas integra globalmente el cuidado del medio ambiente, una sociedad justa y en paz, prosperidad y la evolución hacia un modelo económico más equitativo y e inclusivo para todos, preservando y renovando el capital medioambiental para futuras generaciones.

- Algunos de los objetivos propuestos ya están en marcha. Otros requieren un esfuerzo de multiplicación de los esfuerzos presentes. Pero finalmente otros suponen dar la vuelta a la tendencia actual, incluyendo el objetivo de lograr un calentamiento máximo de $1.5^{\circ}$ para final de siglo, buscando nuevos modelos económicos, productivos y de desarrollo sostenibles, que también permitan reducir la desigualdad, mejorar la inclusión y la vida en los suburbios de las grandes ciudades, proteger el medio ambiente marino, entre otras metas claramente en riesgo en este momento.

- Frente a la declaración de intenciones que suponen los objetivos, ambas agendas presentan retos en cuanto a la equidad de los esfuerzos, impactos y resultados. El balance en los usos de la tierra, el modelo de consumo y producción, la producción y utilización de la energía, especialmente por parte de aquellos que no tienen en la actualidad acceso a un mínimo esencial, el impacto desigual de los efectos adversos del cambio climático y las necesidades de adaptación al mismo, sus implicaciones en las metas de erradicar el hambre, mejorar la producción de alimentos y la seguridad alimentaria o promover el uso de energías renovables, por mencionar algunos. 
- Es en este balance donde la necesaria financiación de las agendas de París y Nueva York carecen, de largo, de la necesaria ambición para alcanzar los objetivos fijados. Es más, el actual desequilibrio entre la dotación destinada a ambos consensos y la magnitud mucho mayor de otras políticas existentes, como por ejemplo las ayudas que aún se dan a las energías fósiles en todo el mundo, ponen en serio riesgo la posibilidad de alcanzar no sólo los ODS que requieren un cambio de tendencia, sino que objetivos ya en marcha como el de reducir las emisiones serán imposibles de obtener si no se mantienen bajo tierra la mayor parte de las reservas de crudo existentes.

- Un escenario sostenible de "cero emisiones" con equidad impone una reforma el actual modelo de desarrollo, cuestionando la viabilidad de las políticas "business as usual", pero también supone un camino repleto de oportunidades de "cobeneficios" como por ejemplo el empleo verde o las mejoras en salud, seguridad y calidad de vida derivadas de un medio ambiente más saludable y una sociedad más equitativa y en paz.

- Finalmente es importante destacar que todos estos cambios requerirán de un gran esfuerzo innovador con la participación de un gran número de diversos agentes, no sólo en lo tecnológico, sino también en los procesos, modelos de negocio y sistemas de gobernanza regional y global, que permitan la creación de las nuevas capacidades, mecanismos e instituciones sobre las cuales asentar este nuevo modelo sostenible de desarrollo humano.

Afrontar con éxito problemas de esta magnitud requiere abordar estos retos en su diversidad, atendiendo a las complejidad interacciones entre los diferentes objetivos que plantean Nueva York y París, actuando con corresponsabilidad y equilibrando cargas y metas entre los países según sus capacidades, potencialidades y objetivos particulares,

Todo ello requiere pasar a la acción respecto de lo acordado en las Cumbres Climática y de Desarrollo Sostenible, poner en marcha y financiar adecuadamente los mecanismos adecuados, involucrar a empresas, instituciones y sociedad civil, fortalecer la participación de las personas, en especial de los más desfavorecidos, controlar, incentivar (y penalizar) eficazmente el cumplimiento (e incumplimiento) de las distintas metas y objetivos, y promover una cultura de sostenibilidad compartida por todos.

\section{BIBLIOGRAFÍA}

ALONSO, J. A. (Dir), SÁNCHEZ, E., RAVINA, L., MATAIX, C., LUMBRERAS, J., LARRÚ, J. M., ... AYUSO, A. (2013), Compromiso Global por un Desarrollo Incluyente y Sostenible. Consideraciones sobre la Agenda Post-2015, SGCID, Madrid. 
BAILIS, R., DRIGO, R., GHILARDI, A., y MASERA, O. (2015), "The carbon footprint of traditional woodfuels", Nature Climate Change, doi:10:1038 / NCLIMATE2491

BRAZILIAN, M., y PIELKE, R. (2013), "Making Energy Access Meaningful”, Issues in Science and Technology, pp. 74-79.

BRUNDTLAND, G. H. (1987), Our Common Future, Oslo. Obtenido de http://www.un-documents.net/our-common-future.pdf

BULUSWAR, S., FRIEDMAN, Z., MEHTA, P., MITRA, S., y SATHRE, R. (2014), 50 Breakthroughts. The 50 most critical scientific y technological breakthroughs required for sustainable global development, U. J. Kumar, Ed., Berkeley, California. Obtenido de https://ligtt.org/50-breakthroughs

DICKENS, C. (1859), Historia de Dos Ciudades, Chapman y Hall, Londres. Obtenido de http://www.revistaideele.com/archivo/node/641

EsF. (2012), Biomasa y Desarrollo. Oportunidades de la biomasa para mejorar el acceso local a la energía en comunidades rurales aisladas de América Latina, Madrid. Obtenido de http://energiasinfronteras.org/images/stories/Estudios/GUIA_BIOMASAbaja.pdf

HALLEGATTE, S., BANGALORE, M., BONZANIGO, L., FAY, M., KANE, T., NARLOCH, U., ... VOGT-SCHILB, A. (2016), Shock Waves. Managing the Impacts of Climate Change on Poverty, World Bank Group, Washington, D. C. Obtenido de https://openknowledge.worldbank.org/bitstream/handle/10986/22787/9781464806735.pdf

IEA. (2011), World Energy Outlook: Energy for All - Financing access for the poor, Paris.

IPCC Grupo de Trabajo II. (2014), Cambio Climático 2014. Impactos, adaptación y vulnerabilidad. Resumen para responsables de políticas. Quinto Informe de Evaluación del Grupo Intergubernamental de Expertos sobre el Cambio Climático, Ginebra, Suiza. Obtenido de https://www.ipcc.ch/pdf/assessmentreport/ar5/wg2/ar5_wgII_spm_es.pdf

IPCC WGIII. (2014), IPCC WGIII Fifth Assessment Report - Mitigation of Climate Change 2014, Berlin, Alemania. Obtenido de http://mitigation2014. org/

LABRIET, M., FIEBIG, C., y LABROUSSE, M. (2015), "Working towards a Smart Energy Path: Experience from Benin, Mali and Togo", Climate and Development Knowledge Network. Inside Stories on Climate Compatible Development, (August). Obtenido de http://cdkn.org/wp-content/ uploads/2015/08/CDKN-HELIO-Inside-Story-Energy-Smart2.pdf

LEE, C. M., CHANDLER, C., LAZARUS, M., y JOHNSON, F. X. (2013), "Assessing the Climate Impacts of Cookstove Projects: Issues in Emissions Accounting", Challenges in Sustainability, vol. 1, núm. 2, pp. 53-71. Doi:10.12924/cis2013.01020053 
LINARES, P. (2014), "ILUC, el cuento de nunca acabar", 29 de abril de 2016. Obtenido de http://pedrolinares.blogspot.com.es/2014/01/iluc-el-cuentode-nunca-acabar.html

NEUMAYER, E. (2003), Weak versus Strong Sustainability. Exploring the Limits of Two Opposing Paradigms, Edward Elgar, Cheltenham Glos, UK. Obtenido de https://www.e-elgar.com/shop/weak-versus-strong-sustainability?__website=uk_warehouse

NICOLAI, S., HOY, C., BERLINER, T., y AEDY, T. (2015), Projecting progress. Reaching the SDGs by 2030, Londres. Obtenido de http://www.odi. org/sites/odi.org.uk/files/odi-assets/publications-opinion-files/9938.pdf

NORTH, D. C. (1992), The New Institutional Economics and Development, St. Louis. Obtenido de http://www2.econ.iastate.edu/tesfatsi/NewInstE. North.pdf

NORTH, D. C. (1993), Nobel Prize Lecture: Economic Performance through Time. Obtenido de http://www.nobelprize.org/nobel_prizes/economicsciences/laureates/1993/north-lecture.html

OMS. (2015), Contaminación del aire de interiores y salud, World Health Organization. Obtenido de http://www.who.int/mediacentre/factsheets/fs292/ es/

ONU (2015), Documento final de la Tercera Conferencia Internacional sobre Financiación para el Desarrollo. Agenda de Acción de Addis Abeba (2015), Naciones Unidas.

ONU (2015), Transformar nuestro mundo: la Agenda 2030 para el Desarrollo Sostenible, Aplicación y seguimiento integrados y coordinados de los resultados de las grandes conferencias y cumbres de las Naciones Unidas en las esferas economica y social y esferas conexas, Naciones Unidas. Obtenido de http:// www2.ohchr.org/spanish/bodies/hrcouncil/docs/gaA. RES.60.1_Sp.pdf

PEZZEY, J. C. V. (1997), "Sustainability Constraints versus "Optimality" versus Intertemporal Concern, and Axioms versus Data on JSTOR", Land Economics, vol. 73, núm. 4, pp. 448-466. Doi:10.2307/3147239

PORTER, M. E., y Kramer, M. E. (2011), "Creating Shared Value”, Harvard Business Review, (January-February). Obtenido de https://hbr.org/2011/01/ the-big-idea-creating-shared-value

RAWORTH, K. (2012), A safe and just space for humanity. Can we live within the doughnut? Oxfam Discussion Papers, Oxford.

ROCKSTRÖM, J., STEFFEN, W., NOONE, K., PERSSON, A., CHAPIN, F. S., LAMBIN, E. F., ... FOLEY, J. A. (2009), "A safe operating space for humanity”, Nature, vol. 461, núm. 7263, pp. 472-475. Doi:10.1038/461472a

SECRETARÍA GENERAL DE COOPERACIÓN INTERNACIONAL PARA EL DESARROLLO, M. de A. E. y C. (2014), Compromiso Universal por un Desarrollo Humano y Sostenible. Posición Española para la 
Agenda Post-2015 (Borrador 4). Obtenido de http://www.cooperacionespanola.es/sites/default/files/posicion_espanola_post2015_borrador_4_31_ julio_2014.pdf

UNITED NATIONS FRAMEWORK CONVENTION ON CLIMATE CHANGE. PARIS AGREEMENT (2015). Obtenido de: https://unfccc. int/resource/docs/2015/cop21/eng/109r01.pdf

UNITED NATIONS SECRETARY-GENERAL. BAN KI-MOON (2015), The Road to Dignity by 2030: Ending Poverty, Transforming All Lives and Protecting the Planet. Synthesis Report of the Secretary-General, Nueva York. Obtenido de https://sustainabledevelopment.un.org/majorgroups/ post2015/synthesisreport

WOLFRAM, C., SHELEF, O., y GETLER, P. (2012), "How will energy demand develop in the developing world?", Journal of Economic Perspectives, núm. 26, pp. 119-38. 